\title{
História ambiental e patrimônio: Construindo caminhos com o turismo
}

\section{Environmental history and heritage: Building pathways with tourism}

\author{
Isabela Barbosa Frederico \\ Universidade Estadual de Campinas, Brasil \\ isabf_tur@yahoo.com.br \\ Pedro Paulo A. Funari \\ Universidade Estadual de Campinas, Brasil \\ ppfunari@uol.com.br
}

\begin{abstract}
Resumo
Inserido nas recentes discussões do século XXI sobre patrimônio e sustentabilidade, este artigo pretende fazer uma discussão teórico-empírica sobre a complexidade da abertura de espaços naturais com culturas locais para o turismo. O estudo de caso apresentado é referente a uma área protegida brasileira com gestão religiosa, chamada Santuário do Caraça. Com uma metodologia de campo construída com observação participante e entrevistas semiestruturadas, buscaremos uma compreensão dos valores locais do território em questão, a mudança do espaço e práticas turísticas no interior da historicidade ambiental e a respectiva complexidade deste processo no passado e no presente. Com esta análise qualitativa, objetivamos somar ao debate que busca construir as relações entre a história e o turismo no âmbito ambiental contemporâneo.
\end{abstract}

Palavras chave: turismo; história ambiental; patrimônio; conservação patrimonial.

\begin{abstract}
In the context of recent 21st century discussions about heritage and sustainability, this article aims to make a contribution to the theoretical-empirical discussion about the complexity of the opening up of natural areas with local cultures for tourism. The case study presented is related to a Brazilian protected area with religious management, called Caraça Sanctuary. With a fieldwork methodology comprising participant observation and semi-structured interviews, we seek an understanding of the local values of the territory in question, the changing of space and tourist practices within the environmental historicity and the respective complexity of this process in the past and present. With this qualitative analysis, we aim to add to the debate that seeks to build the relationships between history and tourism in the contemporary environmental context.
\end{abstract}

Keywords: tourism, environmental history, heritage, heritage conservation.

\section{Introdução}

O presente artigo busca analisar como a cultura existente na Reserva Particular de Patrimônio Natural (RPPN) Santuário do Caraça se reestruturou entre a virada das décadas de 1960 e 1970, a partir de um incidente, no qual a cultura presente se viu diante de uma situação inesperada e teve que se reestruturar, buscando conservar não apenas os seus aspectos históricos, como também o ambiente natural no qual estava inscrita e em constante interação. 
Para tanto, o trabalho está estruturado em três partes. A primeira resgata como marco teórico de análise as premissas da História Ambiental. Em seguida, a reserva do Santuário do Caraça é contextualizada de forma a ilustrar os aspectos biofísicos e histórico-culturais que a tornam emblemática nos estudos vinculados à história e às ciências ambientais. Buscou-se também problematizá-la no contexto de globalização e realizar as aproximações no entendimento das narrativas dos atores envolvidos com o Santuário do Caraça, ${ }^{1}$ na passagem do espaço religioso, para o turístico e natural. Foram inferidos como pressupostos teóricos, o conceito de fronteira de Santos (2002) e as considerações sobre a tradição no processo de globalização, feitas por Giddens (2005). Por fim, a consideração final traz a síntese dos resultados analisados com os possíveis desafios a serem estudados pelos autores em seus trabalhos futuros.

\section{A história ambiental e suas vertentes}

A História Ambiental enquanto campo de estudo nasce em um contexto mais amplo da década de 1960, ${ }^{2}$ quando a questão ambiental brotava no cerne das principais discussões da sociedade. Naquele período, a crítica social se instaurava na contramão dos cenários oriundos do industrialismo e da degradação dos recursos naturais. O planeta se deparava com conferências globais e movimentos ambientalistas que buscavam uma reavaliação e reforma global sobre a crise enfrentada (Florez, 2002; Worster, 1991).

No campo das ciências, a questão ambiental se internalizou desencadeando novas leituras sobre o mundo. Neste processo, história esteve acompanhada de outras disciplinas como o direito, a sociologia, a economia, a filosofia (Drummond, 1991; Worster, 1991). A História Ambiental brota como uma resposta à demanda social moral e política (Pádua, 2012; Worster, 1991).

A emergência da área também respondeu a invocações epistemológicas do próprio campo científico. Existia a necessidade de se romper com a dualidade entre homem e natureza no interior das disciplinas. Pádua (2012) elenca três grandes ranhuras nesse processo, o entendimento de que o ser humano efetua impactos sobre o meio, inclusive a degradação; a renovação dos marcos cronológicos de entendimento do mundo e em terceiro a concepção de história embutida na natureza.

A História Ambiental foi importante na construção e no amadurecimento de questões rígidas existentes no interior da história enquanto área de estudo. Para Palacios (2002), o primeiro elemento que a área problematiza dentro de sua ciência mais ampla, é o tempo. Este elemento nas análises e estudos estava bastante vinculado aos aspectos unicamente humanos, como o surgimento da escrita tradicional (4000 a.C.) e a duração dos governos. Eram incipientes os estudos considerando escalas temporais mais amplas, necessárias à luz das preocupações ambientais, onde as transformações da natureza se desenvolvem em perspectivas mais amplas.

\footnotetext{
${ }^{1}$ As narrativas e as observações aqui apresentadas foram coletadas durante a pesquisa de mestrado da autora, intitulada "Natureza, história e espiritualidade: pelas trilhas do Santuário do Caraça", defendida em 2013 pelo programa de Pós Graduação em Geografia, do Instituto de Geociências, da Unicamp. Neste artigo, buscou-se ampliar o olhar para o debate do Caraça como fronteira, apresentado na dissertação supracitada, com o enfoque teórico da História Ambiental.

${ }^{2}$ A primeira instituição científica da área foi a "American Society for Environmental History", criada em 1977 (Pádua, 2012).
} 
O outro elemento que a História Ambiental procura refletir é a concepção de espaço (Palacios, 2002). Este elemento esteve pautado pela concepção eurocêntrica, ao longo da história ortodoxa do século XIX. Eram considerados importantes as zonas territoriais localizadas nas áreas mais frias do planeta e os trópicos. Já no século XX, essa situação começa a se modificar, a priori com a inserção dos Estados Unidos e posteriormente, com revoluções, como a Mexicana em 1910. O olhar do espaço foi se ampliando e a importância que as florestas tropicais e seus povos tinham na problemática ambiental, ganhava destaque para a posterior História Ambiental.

A terceira faceta que este campo problematiza é a dualidade entre natureza e cultura. Palacios (2002) discorre sobre a relevância de ultrapassar os enfoques analíticos da ciência que consideram uma natureza sem seres humanos, bem como um desenvolvimento dos seres humanos, sem a importância do meio natural. Ambos estão em constante interação e esse constitui o cerne mais relevante de discussão para a História Ambiental, no contexto atual (Leff, 2005; Pádua, 2012; Palacios, 2002).

Com essas três ranhuras apontadas pela História Ambiental, a presente área de estudo tem como foco central a análise do papel e do lugar da natureza na vida humana. Nesse sentido, Worster (1991) aponta três grandes enfoques de estudo da área, que podem ser abordados de forma separada ou em conjunto. São eles, o entendimento de como a natureza se comportou no passado; o domínio sócio-econômico e sua interação com a natureza; a compreensão da percepção, dos valores éticos e nas estruturas de diálogo que compõem o campo de significação da natureza para os indivíduos e grupos culturais. Os estudos envolvendo esses elementos abrem oportunidades para a identificação de cenários alternativos à visão hegemônica de homem devastador (Leff, 2005; Pádua, 2012).

É nesse contexto que os estudos de História Ambiental ganham relevância. Ao incitarem reflexões em torno da interação entre os sistemas cultural e natural, a área pode oferecer não apenas indicativos de como este intercâmbio se deu no passado, mas principalmente os elementos importantes dessa relação para se pensar no futuro (Moran, 2010).

A autora Sedrez (2002) fez um levantamento das pesquisas deste campo no contexto latino-americano. Os três enfoques principais encontrados pela autora foram o encontro entre o novo e o velho mundo; o meio ambiente e a fronteira e o histórico do ambientalismo. Ao longo das publicações em torno da temática da fronteira, a autora enfatiza um eixo de relevância para o presente estudo, que é a "História de Fronteiras". Os estudos com esse olhar buscam a análise dos conflitos em torno dos recursos naturais e segundo a autora eles são incipientes por exemplo em áreas de mineração. Nesse mesmo contexto, encontra-se a RPPN ${ }^{3}$ do Santuário do Caraça, área estudada neste artigo.

\section{Santuário do Caraça: Cenário, conflitos e fronteira}

Este item traz as possibilidades de diálogo dos estudos de fronteira com a RPPN Santuário do Caraça. Para tanto, a mesma será brevemente apresentada, de forma que se compreenda como o cenário pode encontrar na História Ambiental contribuições de análise e de diretrizes futuras para esta área protegida brasileira.

\footnotetext{
3 Reserva Particular de Patrimônio Natural, categoria de Uso Sustentável do Sistema Nacional de Unidades de Conservação (SNUC).
} 


\subsection{A RPPN Santuário do Caraça}

O Santuário do Caraça está localizado no estado de Minas Gerais, entre os municípios de Catas Altas e Santa Bárbara, a 120 quilômetros da capital Belo Horizonte. Com 10.187, 89 hectares, a reserva compõe um dos maciços do chamado Quadrilátero Ferrífero, no início da Serra do Espinhaço. Por esta razão, a unidade esteve entremeada pela exploração de minérios desde o período colonial com o ouro, até os dias atuais com o minério de ferro (Machado, 2008; Mota, 2012). A área se destaca por abrigar uma biodiversidade expressiva, resultante do encontro de dois ecossistemas, a mata atlântica e o cerrado.

O primeiro registro da área se deu no ano de 1708 em um mapa da Província de Minas Gerais. Neste documento, um trecho da Serra do Espinhaço recebia este nome (Zico, 1982). Os registros de sua ocupação no entanto, sugerem que o histórico cultural da área esteve sempre pautado pela religiosidade e espiritualidade. De forma sucinta, podemos dividir a presença humana no santuário em quatro grandes períodos, até os dias atuais. ${ }^{4}$

O primeiro é oriundo de registros historiográficos indicando a presença de bandeirantes na área desde 1700, já demonstrando a relevância da mesma na busca por riquezas minerais (Lopes, Maia, Pereira \& Plastino, 2010; Ottoni, 2012). O segundo corresponde ao que seria o primeiro ato de fundação do território. Através da chegada de um senhor português, conhecido como Irmão Lourenço, foi fundada uma capela barroca e uma hospedaria que recebia peregrinos, irmãos e escravos no ano de 1779. Ao longo desta fase importantes personagens da história passaram pela área como Saint Hilaire, cujas observações sobre a mesma figuram em sua obra "Viagens pelo Interior do Brasil".

Com o passar dos anos, o já debilitado Irmão Lourenço doa as terras que compõem o Santuário do Caraça, para o Rei de Portugal D. João VI, com um pedido para que o Santuário não servisse apenas aos missionários, mas também para a educação de meninos. É nesse contexto que a terceira fase de ocupação se inicia. O rei oferece o lugar, no ano de 1820, para padres portugueses da congregação religiosa vicentina, ${ }^{5}$ que então fundariam neste ano o chamado "Colégio do Caraça".

O colégio teve grande destaque no cenário nacional e foi um importante centro educativo para o estado de Minas Gerais. Por ele passaram cerca de 11 mil alunos, entre eles importantes personagens da história nacional como os já Presidentes da República Afonso Pena e o Arthur Bernardes. O colégio funcionou até o ano de 1968, quando por um incidente vivenciou um grande incêndio e obrigou os padres a finalizarem as atividades educativas. Nesse período, a insegurança se instaurou entre os membros da congregação religiosa que lá existia, pois não sabiam como seguiriam preservando não apenas o território natural onde o colégio se encontrava, mas também os seus traços culturais de peregrinação e educação.

É aqui que se inicia a visitação turística e a quarta fase da área. A princípio com curiosos da região e posteriormente com pessoas vindas de todo Brasil e inclusive do exterior, cuja

\footnotetext{
4 É importante ressaltar que a divisão em etapas constitui apenas uma opção dos autores para esclarecer de forma rápida o histórico de ocupação. No entanto, os estudos realizados na área respeitam a historicidade da mesma, bem como todas as interações ocorridas entre os diferentes momentos de desenvolvimento da unidade.

${ }^{5}$ Os padres que foram ocupar o Caraça eram Leandro Rebelo Peixoto e Antônio Ferreira Viçoso. Eles pertenciam a Congregação da Missão, uma instituição religiosa francesa, cujos padres eram chamados de vicentinos ou lazaristas. Essa organização tinha como preceitos a participação em missões, paróquias, colégios, e também a constante ajuda aos pobres através de ensinamentos e educação (Afonso, 2012; Zico, 1982).
} 
passagem pelo Santuário do Caraça compunha os roteiros integrados aos demais atrativos do estado de Minas. A visitação pública da área foi compreendida pelos padres como uma possibilidade de continuação de seus ideais. A princípio, na década de 1970, a atividade não teve planejamento prévio, mas com o decorrer dos anos, os padres em constante diálogo e aprendizado com a nova realidade que se instaurava foram criando estratégias para que 0 turismo pudesse se desenvolver aliado aos preceitos na unidade.

Um bom exemplo disso foi a criação da Comissão "Pró-Caraça" em 1973, na qual foram estabelecidos os pilares da reconstrução da área, que seriam peregrinação, cultura e turismo. Nesse âmbito cabe ressaltar a importância que os padres atribuíam ao entorno natural do colégio, cujo espaço estava em constante interação com a religiosidade do local (Zico, 1982). Apesar de existirem tentativas de tornar a unidade como um parque natural desde 1980, apenas em 1994 o Santuário do Caraça foi elevado a Reserva Particular de Patrimônio Natural, constituindo assim uma unidade de conservação privada.

\subsection{A cultura do Santuário do Caraça e o processo de globalização}

O caso do Santuário do Caraça se mostra bastante emblemático para os estudos de História Ambiental, uma vez que configura uma situação na qual o espaço natural está em constante diálogo com o cultural, além dos registros históricos de ocupação da área mostrarem que a presença humana, vinculada a uma religiosidade, buscou estratégias para conservar não apenas os elementos históricos, mas também a natureza circundante, que já esta foi e segue sendo ameaçada por contextos econômicos vinculados à mineração.

Para Pádua (2012) a discussão ambiental na cultura contemporânea não está enfocada apenas nos elementos da natureza, mas principalmente na forma pela qual, as sociedades humanas se territorializam, e edificam os seus ambientes em torno das relações com os espaços físico-biológicos do planeta. Ao redor do planeta temos uma grande diversidade de concepções culturais e simbólicas em relação ao mundo natural. A maneira como diferentes grupos humanos e comunidades se posicional e se relacionam na prática com o espaço no qual vivem é, em grande parte, influenciada por essas concepções.

Nesse sentido, o Santuário do Caraça emerge como exemplo interessante de análise, principalmente a partir de sua quarta fase, com o turismo. Compreender as concepções e práticas que envolvem a interação da cultura religiosa do local - instaurada desde o século XVIII no local - com a área natural, e a razão pela qual a mesma, em um período de incertezas, como o incêndio de 1968, optou por seguir instaurada na área, são questões interessantes de análise, quando existe o anseio de se pensar formas alternativas de interação com a natureza, bem como estratégias de conservação da mesma.

Além disso, outros questionamentos parecem emergir, como exemplo a influência do turismo no contexto do patrimônio cultural (material e imaterial) existente. $O$ contato com a alteridade repercute na possibilidade de modificações de percepções e ideais. Dentro do turismo, Dias (2006) enfatiza que as interações entre visitante e visitado geram mudanças em todos os atores que participam deste processo, criando um ambiente complexo de análise. Essas relações podem gerar impactos positivos e/ou negativos concomitantes um ao outro. No entanto, por ora é importante salientar que no cenário do Santuário do Caraça o turismo parece exercer também um importante instrumento econômico para os padres manterem sua cultura na constante interação com a área natural.

A questão cultural bem como as concepções simbólicas sobre a natureza no interior do Santuário, tampouco estão desvinculadas do contexto de globalização. Giddens (1999) 
esclarece que a o processo de globalização, amadureceu a partir do desenvolvimento nos sistemas de comunicação iniciados no final da década de 1960 e, para além do enfoque econômico, influencia também os aspectos políticos, tecnológicos e culturais.

O processo de globalização afeta a reserva aqui pesquisada em diferentes escalas. No entanto, gostaríamos de ampliar neste artigo o olhar para as mudanças no âmbito cultural da unidade. Por um lado, temos como o turismo - facilitado e consolidado na atualidade em detrimento do desenvolvimento da tecnologia e da própria globalização - tende a induzir e criar outros modos de vida e interesses no interior da reserva. Além disso, cabe refletir também como a identidade tradicional religiosa existente se comporta e é influenciada pelo contexto global.

Giddens (2005) traz elementos importantes para esta análise. O primeiro deles constitui no esclarecimento deste processo como não singular e bastante complexo, no qual as identidades ora se diluem na arena global, ora se fortalecem e ressurgem em várias partes do mundo. Contudo, este processo de emergência de identidades locais se dá de forma anárquica e bastante influenciada pelo encontro com o outro, ganhando novos contornos a partir da diferença.

A identidade e a tradição no contexto da globalização parecem estar não mais duras e inflexíveis, mas sim inseridas em um contexto difuso e dinâmico (Santos, 1993). Sendo assim, analisar as memórias do Santuário do Caraça e as influências do ambiente natural nas suas narrativas e historicidade, implicam também em problematizar o contexto mais amplo no qual a unidade está inserida, bem como compreender as mudanças que a alteridade oriunda do turismo, provoca nos processos de transformação da sua identidade religiosa e da concepção de natureza embutida nesta.

Considerando, todavia, a questão ambiental, faz-se importante considerar a inexistência no contexto atual de uma natureza e cultura puras. É nesse sentido, que Giddens (2005) explora a ideia do fim de tradição, não no sentido de desaparecimento, mas sim no encontro desta com o outro, reverenciado pelos inúmeros processos globais. Florescem assim, tradições renovadas em versões diferentes.

A temática da identidade, bem como a percepção e simbologias inseridas nesta, parecem vivenciar na atualidade, um constante conflito. O processo de globalização ao facilitar o trânsito entre as fronteiras físicas, demonstra também resultar em elementos difusos da fronteira do tradicional no contexto cultural. Ao considerarmos a História Ambiental e os seus anseios em compreender a interação humana com a natureza, bem como a concepção da primeira em relação à segunda ao longo do tempo, temos a necessidade de analisar as "contradições de lugares e as experiências vividas", em muitos casos a partir de recortes geográficos e biofísicos concretos (Pádua, 2012: 35).

Para tanto, o artigo trará no próximo item as aproximações realizadas com membros da dinâmica do Santuário (padres, coordenação ambiental, turistas) que permitem explorar as concepções do ambiente local e as dinâmicas surgidas a partir do final do colégio em 1968 e início da atividade turística, enquanto estratégia de resiliência e renovação da cultura local, frente à problemática ambiental daquele período. Desta forma, os dados oriundos das entrevistas e da observação participante empreendida na área, buscam analisar o espaço do Santuário do Caraça na transição de espaço religioso para espaço turístico, à luz do conceito de fronteira de Santos (2002), interagindo com as ideias empreendidas por Giddens (2005) sobre a tradição no processo de globalização. 


\subsection{O Santuário do Caraça como fronteira}

Além da heterogeneidade detectada entre aqueles que chegam ao local, observamos um Santuário como resultado de interesses que se entrelaçam produzindo situações curiosas.

Para o campo da História Ambiental, Pádua (2012: 31) confirma a necessidade de darmos importância ao ser humano, quando empreendemos um olhar sobre o mundo biofísico. Os estudos devem considerar que este último não se apresenta de forma "direta, positiva e imediata à percepção humana", uma vez que nossos atos estão sempre pautados por sentidos e compreensões de mundo. Desta forma, a interação com os recursos naturais e a valorização de determinadas paisagens e espaços, expressam de forma clara uma historicidade.

Os usos do espaço do Santuário do Caraça refletem os efeitos dinâmicos intrínsecos à historicidade. Focaremos aqui no período após 1968, no qual a chegada do turismo cria oportunidade e confrontação para com o espaço e a subjetividade religiosa existente criando processos de reinvenção na busca pela conservação patrimonial (cultural e natural). Desta forma, propomos o Santuário como espaço de fronteira. Bruhns (2007: 87), ao colocar a natureza como tal, define:

Pensar a natureza como espaço de fronteira significa que esta está mal delimitada, portanto, imprecisa. As relações sociais estabelecidas aí terão características de inovação e instabilidade, pois os que chegam trazem hábitos e os que já estão reconhecem na diferença oportunidades de enriquecimento. Oportunidades facilitando novos relacionamentos, novas invenções de sociabilidade, que se transformam em algo herdado, de onde se alimentam sucessivas identificações, que se agruparão por memórias mais ou menos traiçoeiras, constituindo o que é designado por identidade.

O novo público provocou um sentimento de flexibilidade na tradição Caracense. Um exemplo é a relação com as tradicionais missas diárias. Estas continuam sendo realizadas, contudo a obrigatoriedade da presença não é requisitada entre àqueles que visitam o local. Em um contexto mais amplo da tradição, Giddens (2005) nos ajuda com a compreensão deste cenário. Para o autor, o contexto onde a tradição está inserida pode mudar, no entanto, esta, dotada de uma verdade, fornece uma estrutura para a continuidade no encontro com o outro. A modernidade implica em cada vez menos vivermos a tradição de maneira tradicional, ou seja, através unicamente de seus rituais e simbolismo, mas sim no encontro dos seus limites com o da alteridade.

Contudo, a chegada do novo não é imune a conflitos, como sucede em todos os processos de reinvenção. Pereira e Carrieri (2005) enfatizam a ampliação dos papéis assumidos pelos padres. Somam-se as atividades econômicas às tradicionais educativas e religiosas. Contudo, os valores que lapidam a gestão do novo espaço turístico também permeiam os pilares identitários da histórica do Santuário do Caraça. Em conversa com um dos padres, ele resgata as bases na qual o Santuário foi pensando na década de 1970: Peregrinação, cultura e turismo. Desta forma, ele reflete como o viés educativo esteve sempre presente na cultura Caracense, desde os primórdios com as passagens de inúmeros pesquisadores na área até os dias atuais, onde ele pontua "hoje os nossos alunos são vocês", referindo-se aos turistas presentes.

A vida na fronteira para Santos (2002: 348) se caracteriza pelo "Uso Selectivo e Instrumental das Tradições", no qual as tradições se revestem das novidades oriundas do novo. $O$ espaço religioso do Santuário do Caraça nesse sentido se amplia e inclui um conceito mais amplo de peregrinação. A fala da coordenadora ambiental exemplifica: 
Vou dar um exemplo. Vou fazer uma comparação com Nossa Senhora Aparecida. Ali você vê que é um santuário com um único objetivo de peregrinação, as pessoas só vão ali para rezar, para buscar Deus, né. No caso do Santuário do Caraça, a gente fala que ele é mais complexo, porque tem pessoa que não vem só pela igreja, mas vem por um passeio, um passeio com a família, né. Mas querendo ou não, acaba sendo envolvida pela obra de Deus.

A busca por um Deus que anteriormente residia na compreensão católica também é ampliada para os cânones da natureza circundante. Observamos na continuidade do discurso da coordenadora:

Ahh como dizem né, isso é particular de cada um. Às vezes é uma simples planta, ou um arco íris, ou um dia que a serra brilha mais. Então é assim, isso varia muito. Às vezes um acontecimento que, por exemplo, alguém se machuca e como as coisas aconteceram para ela ser atendida, medicada, ela acredita que foi uma obra de Deus.

Entretanto, os conflitos entre o espaço religioso e turístico são proeminentes. $\mathrm{Na}$ atualidade, conforme observações em trabalho de campo identificamos um público com motivações heterogêneas, as quais podem gerar conflitos no interior do grupo de visitantes, bem como na relação destes com os preceitos religiosos pré-existentes. Estes, comuns a espaços de fronteira, são destacados por Santos (2002: 348) como novas formas de sociabilidade:

Viver na fronteira significa ter de inventar tudo, ou quase tudo, incluindo o próprio acto de inventar. [...] Na fronteira, vive-se da sensação de estar a participar na criação de um novo mundo. As reservas de experiência e de memória que cada pessoa ou grupo social leva consigo para a situação da fronteira transformam-se profundamente quando aplicadas num contexto completamente novo [...].

Esse cenário pode ser analisado também pela reflexão que Giddens (2005: 55) faz sobre as tradições religiosas na modernidade. $\mathrm{O}$ autor discute como no mundo cosmopolita "mais pessoas do que nunca estão regularmente em contato com outras que pensam de maneira diferente delas". Nesse sentido, concomitante aos papéis mutáveis da tradição, são inferidas no nosso cotidiano, novas dinâmicas que mergulham em uma relação complexa entre "autonomia de ação e compulsividade por um lado, e entre cosmopolitismo e fundamentalismo pelo outro". No momento quando a tradição é confrontada, a realidade demanda uma experiência mais aberta e reflexiva.

Cabe ressaltar que no contexto do Santuário pesquisado, a gestão de padres entrevistada ressaltou a abertura ao novo em um diálogo constante com os pilares (peregrinação, cultura e turismo) que conformam a tradição do espaço, buscando não descaracterizar o local nos processos de reinvenção de uso e ocupação do espaço. Este fenômeno remete para a subjetividade de fronteira descrita por Santos (2002: 354), no qual o novo percurso se orienta ora pelo paradigma dominante, ora pelo paradigma emergente. Desejando alcançar o segundo, sabe-se que é necessário navegar "ziguezagueando", contudo, sempre mantendo um olhar no primeiro para guiar-se. Fenômeno este relacionado com as navegações de cabotagem descritas pelo autor.

A discussão de tradição empreendida por Giddens (2005) traz elementos substanciais para a análise. Ao contrário do que o lluminismo buscava, o autor reafirma a importância das 
tradições na sociedade, uma vez que estas dão continuidade e base à vida. Seguir um caminho totalmente eclético constituiria uma passagem sem foco e direção. Contudo, na modernidade a tradição acarreta novos comportamentos que extrapolem o "tradicional" e encontrem novos fundamentos na interação ativa com outras formas de vida. Assim, elas logram a sua continuidade à medida que são justificadas no momento da comparação com o diferente.

A relação de cabotagem pode ser observada nos papéis de gestores assumidos pelos padres. Ao longo dos processos de contratação de funcionários para os serviços turísticos são os padres quem intermediam e protagonizam as escolhas, embora exista na atualidade, um profissional de recursos humanos que os auxilie neste processo.

Pereira e Carrieri (2005) identificaram a presença substancial dos valores sociais ao invés dos puramente econômicos na contratação de funcionários. Existe na gestão do Santuário, uma preferência por oferecer treinamento aos funcionários provenientes das redondezas, do que os substituir por mão de obra mais qualificada que esteja longe da região. Com isso, existe uma busca pela redução da desigualdade e da exclusão. Desta forma, segundo os autores, há um afastamento das relações de troca comerciais entre clientes e vendedores característica das empresas contemporâneas.

Os efeitos dessa relação são percebidos de forma qualitativa pelos turistas que destacam em seus discursos a relação de amabilidade construídas entre eles e as pessoas que trabalham no local. Este efeito inclusive garante, segundo discursos coletados, o desejo pelo retorno ao local em outras oportunidades. Conforma observamos na fala do hóspede M. carioca, bacharel em direito, visitante de uma década do santuário:

Eu não consigo ficar sem vir aqui. Uma vez fiquei um ano e jurei pra mim mesmo que nunca mais faria isso. O Santuário do Caraça é isso daqui, essa relação calorosa, essa conversa entre as pessoas, esse carinho do pessoal que trabalha aqui, essa desaceleração de tudo.

Nas trilhas dos novos papéis assumidos pela direção do Santuário, a coordenação ambiental faz um relato interessante:

Eu não sei se eu comentei com você, mas cada dia a gente vai vivenciando uma situação diferente, né. A questão é de orientação jurídica por falta de uma placa. Aconteceu num parque nacional, a pessoa escorregou numa cachoeira e quebrou a bacia, ela automaticamente moveu um processo contra o governo. Ela só não ganhou a causa, porque o parque provou pra ela que tinha uma placa ali dizendo que era um local escorregadio. Essa foi a palestra de um promotor de justiça no Rio em um congresso de montanhismo. Então, se não fosse aquela placa, a pessoa teria ganho o processo. Uma vez que você abre as portas pra visitação e cobra por um serviço, quem responde por essas pessoas é a empresa. Não responderia se você não cobrasse. Mas como manter a área se não cobrarmos? Como você seleciona um público? Querendo ou não seremos reféns de placas, mas assim evitando a poluição visual.

Isso nos remete ao que Santos (2002: 350) chama de caráter de promiscuidade de estranhos e íntimos, de herança e invenção. Estar na fronteira segundo o autor, exige de forma poética, esperar "por quem quer que seja incluindo Godot". Isso inclui a importância dada a todos que chegam, incluindo a sua subjetividade, como alternativa de encontrar na diversidade as "oportunidades para o enriquecimento mútuo". Existe no discurso da coordenadora a oportunidade de melhorar a infraestrutura não apenas para o visitante, mas 
também na busca por evitar impactos na própria estrutura física e imaterial da reserva. Observamos também outro espaço na relação com o turístico e o religioso, ou seja, o natural (em forma de RPPN).

Observamos então os diferentes usos e concepções lapidando o espaço total do Santuário do Caraça. De um lado temos o espaço sagrado, congregando religião, espiritualidade e natureza e de outro àquele considerado profano, desenhado pelo turismo. Contudo, este último possibilita a conservação do primeiro através de processos dinâmicos de reinvenção e construção identitária, abrindo novas possibilidades em relação à tradição. As subjetividades transitam não apenas remodelando o patrimônio material, mas também o espaço simbólico daqueles que o experienciam nos seus mais diferentes interesses e ações.

Sendo assim, o cenário observado no Santuário do Caraça enquanto espaço de fronteira, parece caminhar no sentido proposto por Giddens (2005) no âmbito da tradição na modernidade. Ao passo que o enfoque da tradição transita no encontro com a alteridade, novas dinâmicas são inferidas no seu cerne, gerando espaços de maior liberdade e autonomia, porém de igual forma dotados de certa imprevisibilidade e complexidade. Ao congregar o turismo como mais uma atividade do seu espaço, a reserva se confronta com novas percepções e ideias, cuja interação necessita estar em constante reflexão, a fim de que valores importantes do seu grupo cultural não se percam neste processo.

\section{Considerações finais}

Este trabalho buscou as primeiras aproximações com o turismo do Santuário do Caraça, pois justamente objetivou realizar um mapeamento das diferentes valorações do espaço da unidade, de forma que a compreensão dos usos respectivos fosse facilitada. No âmbito da História Ambiental, conforme nos evidenciou a bibliografia apresentada, faz-se importante entender e analisar as diversas simbologias e percepções culturais em relação ao ambiente, pois estes nortearão as ações sobre o mesmo.

No caso do Santuário, observamos um território biofísico peculiar, onde existe o encontro de ecossistemas relevantes como a mata atlântica e o cerrado, que conferem ao local uma biodiversidade expressiva. Contudo, o espaço também se insere em um contexto emblemático, de intensa exploração por mineração, o que acaba inferindo em constantes ameaças ao patrimônio em questão. E nesse intermédio, está uma cultura religiosa, cujo vínculo com o espaço já se dá há três séculos, desenhando as formas de uso com o mesmo. No entanto, outro elemento importante também desponta nessa complexidade, que é o uso turístico, presente desde o início da década de 1970, período em que o mundo experimentava embates com a questão ambiental com enfoques políticos e de movimentos contraculturais.

O turismo pelas primeiras aproximações observadas na subjetividade de fronteira, parece despontar como elemento fundamental na atual conjuntura da unidade. Ao passo que atua como possibilidade real de manutenção econômica da área pela congregação religiosa, repercute também na apropriação do espaço natural, bem como na reestruturação da tradição existente, no contexto mais amplo da modernidade e da globalização. Esse cenário, difuso e complexo, gera instabilidade ao mesmo tempo que propõe uma oportunidade de continuidade da cultura local interagir com o espaço natural. Para além de dualidades nesse aspecto, observamos imbricações relevantes para estudos futuros. Começam a emergir questionamentos como, em que medida o turismo pode configurar-se como estratégia de aperfeiçoamento da conservação de áreas patrimonais? Além de, como determinadas culturas 
se comportam para defender sua tradição e o seu ambiente, em contextos mais amplos de globalização e intenso debate ambiental, na arena global?

A compreensão dessas interações entre o local e o global, a partir de análises empíricas de contextos regionais específicos parece ser uma opção dentro dos estudos de História Ambiental (Drummond, 1991; Leff, 2005; Pádua, 2012; Sedrez, 2002). No entanto, estes estudos demandam um enfoque que ultrapasse o campo disciplinar e se estruture na interação com outras áreas do conhecimento. Drummond (1991) aponta o diálogo com as ciências naturais, o sentido de se compreender por exemplo, as nuances que a ecologia de paisagem possibilita para análise do território na escala temporal. Assim, os dados podem interagir constantemente com os elementos qualitativos oriundos das memórias e narrativas coletadas. Outro enfoque citado pelo autor que parece ser relevante para os estudos do Santuário do Caraça é o entendimento dos ciclos econômicos nacionais. Nesse interim, poderíamos repensar como a exploração de recursos minerais influencia no território da reserva em questão, ampliando e aprofundando as análises empreendidas.

A passagem do espaço religioso para o turístico, durante a década de 1970, bem como a permanência desta atividade (turística) até os dias atuais - facilitando a permanência do Santuário, bem como seus aspectos culturais e naturais -, configuram-se como questões interessantes de estudo para a atual conjuntura da problemática ambiental. Isto é, o turismo se mostra como uma possível atividade capaz de fomentar processos de conservação natural, através da participação dos valores culturais na gestão.

Para além do bem e do mal, o turismo facilita a interação entre diferentes culturas durante o encontro entre visitante e visitado. A atividade hoje é um dos grandes setores de serviço que foi amplamente facilitado pelo processo de globalização. As barreiras geográficas parecem ser momentaneamente diluídas nessas experiências, e como assinala Santos (2005: 48) a intensificação de contatos "abriu novas oportunidades para o exercício da tolerância", contudo é real também que "têm surgido novas formas e manifestações de intolerância, chauvinismo, de racismo, de xenofobia e, em última instância, de imperialismo. ". O futuro, portanto, é eminentemente desenhado pelo risco. O mundo no contexto de modernidade não fica limitado em uma única área territorial, mas se faz sentir mundialmente e isso implica consequências para a tradição (Giddens, 2005).

É nesse contexto complexo que a realidade do Santuário do Caraça parece estar se desenvolvendo. Considerando esses elementos que lhe conferem um viés peculiar de análise, é importante ressaltar que a partir dos questionamentos aqui apresentados, o estudo na mesma terá continuidade nas pesquisas dos autores deste trabalho. Sendo assim, a História Ambiental apresentada como marco teórico propõe de fato, que o estudo das transformações do ambiente no passado constitua exercício fundamental para se pensar o futuro (Florez, 2002; Moran, 2010). De forma bastante clara, observamos um diálogo entre patrimônio cultural e desenvolvimento sustentável em amplo curso e importante desenvolvimento.

\section{Referências bibliográficas}

Afonso, J. (2012). Santuário do Caraça. Revista Sagarana, p. 40.

Bruhns, H.T. (2007) A ideia de natureza como fronteira. In C. Serrano, H.T. Bruhns \& M.T.D.P. Luchiari (Eds.), Patrimônio, natureza e cultura. Campinas: Papirus.

Dias, R. (2006). Turismo e patrimônio cultural: Recursos que acompanham o crescimento das cidades. São Paulo: Saraiva.

Drummond, J. A. (1991). Para fazer história ambiental: Temas, fontes e linhas de pesquisa. Estudos Históricos, 4 (8), 177-197. 
Florez, A. G. (2002). La história ambiental frente a las ciencias sociales. In G. Palacio, \& A. Ulloa (Eds.), Repensando la naturaleza: Encuentros y desencuentros disciplinarios en torno a lo ambiental. Colombia: Universidad Nacional de Colombia.

Giddens, A. (1991). As consequências da modernidade. (Trad. R. Fiker). São Paulo: Universidade Estadual Paulista.

Giddens, A. (2005). Mundo em descontrole. (Trad. M. L. X. A. Borges) Rio de Janeiro: Record.

Leff, E. (2005). Construindo a história ambiental da América Latina. Revista Esboços UFSC, 12 (13).

Lopes, D. A., Maia, M. da. G. M., Pereira, D. de C. \& Plastino, M. R. (2010). Ecoturismo, cultura e comunidades: Reflexões sobre o entorno da RPPN Santuário do Caraça (MG). Revista Brasileira de Ecoturismo, 3 (3), 382-407.

Machado, A. C. A. R. (2008) Ecoturismo na Serra do Caraça: Contribuições da interpretação para a conservação ambiental. (Trabalho de conclusão de Curso de Bacharelado em Turismo), Universidade Federal de Minas Gerais, Belo Horizonte.

Moran, E.F. (2010). Adaptabilidade humana: Uma introdução à antropologia ecologica (2 $2^{a}$ edição). São Paulo: Universidade de São Paulo e Editora Senac.

Mota, R. C. (2012). Flora I - Serra do Caraça: Texto básico sobre sua flora. In C. Ottoni, Serra do Santuário do Caraça. Belo Horizonte: V \& M do Brasil.

Ottoni, C. (2012). Serra do Caraça. Belo Horizonte: V \& M do Brasil.

Pádua, J. A. (2012). As bases teóricas da história ambiental. In J. L. A. Franco, S. D. Silva, J. A. Drummond \& G. G. Tavares (Eds.), História ambiental: Fronteiras, recursos naturais e conservação da natureza. Rio de Janeiro: Garamond.

Palacios, G. (2002). História tropical: A reconsiderar las nociones de espacio, tempo y ciência. In G. Palacio \& A. Ulloa (Eds.), Repensando la naturaleza: Encuentros y desencuentros disciplinarios en torno a lo ambiental. Colombia: Universidad Nacional de Colombia.

Pereira, D. \& Carrieri, A. P. (2005). Espaço religioso e espaço turístico: Significações culturais e ambiguidades no Santuário do Caraça/MG, Organizações \& Sociedade, 12 (34), 31-50.

Santos, B. de S. (1993). Modernidade, identidade e a cultura da frontera. Tempo social, Rev. Sociol. USP., São Paulo, 5 (1-2), 31-52.

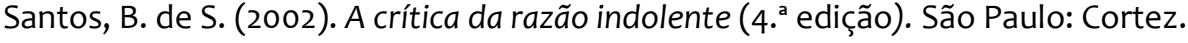

Santos, B. de S. (2005). Os processos de globalização. In B. de S. Santos. A globalização e as ciências sociais ( $3^{a}$ edição). São Paulo: Cortez.

Sedrez, L. (2002). História ambiental de América Latina: Orìgenes, principales interrogantes y lagunas. In G. Palacio \& A. Ulloa (Eds.), Repensando la naturaleza: Encuentros y desencuentros disciplinarios en torno a lo ambiental. Colombia: Universidad Nacional de Colombia.

Worster, D. (1991). Para fazer história ambiental. Estudos Históricos, 4 (8), 198-215.

Zico, J. T. (1982). Caraça: Peregrinação, cultura, turismo. Minas Gerais: Instituto Histórico e Geográfico de Minas Gerais.

ISABELA BARBOSA FREDERICO é Bacharel em Turismo pela Universidade Federal de São Carlos (2009), mestre em Geografia pela Universidade Estadual de Campinas (Unicamp) e doutoranda em Ambiente e Sociedade, também pela Unicamp, com apoio institucional e financeiro da Coordenação de Aperfeiçoamento de Pessoal do Nível Superior). Foi estudante visitante da Escuela Superior de Turismo, do Instituto Politécnico Nacional, México, durante a realização do mestrado. Atualmente se dedica aos temas de pesquisa vinculados ao turismo, espiritualidade e proteção da natureza, com um estudo de caso realizado na Reserva Particular de Patrimônio Natural "Santuário do Caraça", no estado de Minas Gerais, Brasil. Endereço institucional: Núcleo de Estudos e Pesquisas Ambientais/UNICAMP, Rua dos Flamboyants, 155, Cidade Universitária, Campinas, SP - cep: 13.083-867, Brasil.

PEDRO PAULO A. FUNARI é Bacharel em História (1981), mestre em Antropologia Social (1986), doutor em Arqueologia (1990), pela USP, livre-docente em História (1996) e Professor Titular (2004) da Unicamp. Professor de programas de pós da UNICAMP e USP, Distinguished Lecturer University of Stanford, Research Associate - Illinois State University, Universidad de Barcelona, Université Laval (Canadá), líder de grupo de pesquisa do CNPq, assessor científico da FAPESP, orientador em Stanford e Binghamton, foi colaborador da UFPR, UFPel, docente da UNESP (1986-1992) e professor de pós das Universidades do Algarve (Portugal), Nacional de Catamarca, del Centro de la Provincia de Buenos Aires 
e UFRJ. Tem experiência na área de História e Arqueologia, com ênfase em História Antiga e Arqueologia Histórica, além de Latim, Grego, Cultura Judaica, Cristianismo, Religiosidades, Ambiente e Sociedade, Estudos Estratégicos, Turismo, Patrimônio, Relações de Gênero, Estudos Avançados. Endereço institucional: Núcleo de Estudos e Pesquisas Ambientais/UNICAMP, Rua dos Flamboyants, 155, Cidade Universitária, Campinas, SP - cep: 13.083-867, Brasil.

Submetido em 15 setembro 2016

Aceite em 29 março 2017 